\title{
Towards safer foods and more democratic decisions Is this a contradictory goal?*
}

\author{
Ariane KÖNIG \\ James Martin Institute \\ for Science and Civilization, \\ Saïd Business School, Oxford University \\ <ariane.koenig@martininstitute.net>
}

\begin{abstract}
Since the mid-1990s and the BSE crisis food safety policy is a priority of the EU. In practise there are however many hurdles towards implementing principles of improved governance, such as transparency and greater participation, especially at EU-level. This paper presents the work of the SAFE FOODS prospect towards the development an improved framework for risk analysis. The final aim is to develop concrete recommendations on how to facilitate coordination between risk assessors, risk managers and stakeholders across the EU, and to keep methods for risk assessment apace with developments in the life sciences.
\end{abstract}

key words: food safety, risk analysis framework, risk assessment profiling, probabilistic modeling, transparency and accountability

\section{International and EU risk analysis frameworks}

dues or BSE, can cross borders with trade, making the protection of public health through food safety regulation a transnational endeavour.

Internationally recognised frameworks for risk analysis not only make decision-procedures within one jurisdiction more consistent and transparent, but they also facilitate collaboration amongst governments to reduce foodrelated illness and death. This paper develops an improved risk analysis framework building on the analysis of current risk analysis models and approaches to food safety implementation in practise.

In spite of a fundamental overhaul of the EU food safety system that was started in 1997 at the peak of the BSE crisis and continued with Romano Prodi's initiative, there is still considerable need for improvement. Discussions at the highest political level have highlighted the need for improved communication with the public and better coordination between risk assessors, managers and EU-level and national authorities [1].

The objective of the SAFE FOODS project is to enhance transparency and accountability of the current EU food safety system, whilst keeping the focus of decision-making on the protection of public health. The project develops an improved framework for risk analysis to facilitate coordination between risk assessors and risk managers, and stakeholders, and to keep methods for risk assessment apace with developments in the life sciences.

\footnotetext{
This article is not to be considered as the official presentation of the SAFE FOODS project
}

Most governments today approach risk-based regulation through a shared understanding of the process of risk analysis that is based on a 1983 report of the National Research Council [2]. This framework was further elaborated by international expert groups under the auspices of the Codex Alimentarius Commission, the Food and Agricultural Organisation, and the World Health Organisation. Codex standards, guidelines and recommendations reflect an international consensus on the requirements to protect human health from food-borne hazards that is officially recognised by the World Trade Organisation (WTO) ${ }^{1}$. Most governments therefore closely follow the process for risk analysis as set forth by the Codex Alimentarius Commission (CAC).

In this framework, decision-making is conventionally broken down into the following steps: risk assessment, or 'the determination of the likelihood of the occurrence and potential magnitude of harm'; risk management, or 'the process of weighing, selecting and implementing policy alternatives in the light of risk assessment'; and risk communication [3, 4]. According to the Joint Expert Consultation on Risk Communication interactive communications are essential to identify social, economic, religious, ethical, and other concerns, so that these can be openly considered and addressed. Interested parties should, within reason, be involved in identifying management options, developing the criteria for selecting those

\footnotetext{
$\overline{1}$ The World Trade Organisation's Final Act included the "Agreement on the Application of Sanitary and Phytosanitary Measures" and referred to in the Agreement on technical barriers to trade.
}

options and providing input to the implementation and evaluation strategy. Decisions should then be clearly communicated to all interested parties.

One fundamental principle of the Codex framework is the separation of risk management and risk assessment activities. The management is done by the Commission of representatives of Member States and the assessment is done by Scientific Committees of 'independent' scientific experts asked not to consider any national or other interests. The risk managers initiate and end the process. The process is iterative: decisions are periodically reviewed, taking into account new knowledge (for instance on a technology's application, new microbiological or toxicological data or new patterns of exposure) and results from monitoring the implementation of past decisions.

Since the reform of the EU food safety system in 1997 there is also a policy of strict separation of risk assessment and risk management, as under the CAC [5]. This change was reinforced by the EU General Food Law of 2002 that establishes the European Food Safety Authority for providing risk assessments. Decisions under EU food law are usually taken by 'regulatory committees' with representatives of competent authorities of the EU Member States; these processes are administered by the European Commission (exact provisions depend on the secondary legislation the foodstuffs fall under). However, current arrangements are not perfect. A high level expert body criticised the current approach to separating risk assessment and management, by saying this is not feasible in practise, and that quality of life criteria should be considered in risk assessment as well as in risk management. It recommended to "develop formal means by which issues such as animal welfare, quality of life, socioeconomic considerations and sustainability can be incor- 
Table 1.

\begin{tabular}{|c|l|l|l|}
\hline \multicolumn{5}{|c|}{ Gaps between principles and practice } \\
\hline Stage & \multicolumn{1}{|c|}{ Policy document } & \multicolumn{1}{|c|}{$\begin{array}{c}\text { Principles } \\
\text { of good governance }\end{array}$} & $\begin{array}{l}\text { Current practice } \\
\text { in food safety } \\
\text { governance }\end{array}$ \\
\hline \multirow{2}{*}{ Framing } & $\begin{array}{l}\text { Better Regulation Package } \\
\text { EU SSC Report on Risk } \\
\text { Assessment }\end{array}$ & $\begin{array}{l}\text { Participato ry framing } \\
\text { for shared } \\
\text { understanding of } \\
\text { objectives }\end{array}$ & $\begin{array}{l}\text { No formal framing } \\
\text { step }\end{array}$ \\
\hline Assessment & $\begin{array}{l}\text { EU SsC Report on Risk } \\
\text { Assessment } \\
\text { Communication on } \\
\text { Precautionary Principle }\end{array}$ & $\begin{array}{l}\text { Consider impacts on: } \\
\text { - Health (risk/benefits) } \\
\text { - Environmental } \\
\text { - Social } \\
\text { - Economic } \\
\text { - Ethical }\end{array}$ & $\begin{array}{l}\text { Quasi-exclusive focus } \\
\text { on health and } \\
\text { environmental risks }\end{array}$ \\
\hline Decision-making & $\begin{array}{l}\text { Gssessment } \\
\text { Communication on } \\
\text { Precautionary Principle }\end{array}$ & $\begin{array}{l}\text { Participato ry process } \\
\text { for ranking decision } \\
\text { options }\end{array}$ & $\begin{array}{l}\text { Informal consultation } \\
\text { at discretion of } \\
\text { officials }\end{array}$ \\
\hline
\end{tabular}

porated in the risk assessment process." The quality of life concept [6] can also include concerns about animal welfare, equity impacts, environmental impacts, aesthetics, ethics, and cultural and community identity. The stated ultimate goal of inclusion of such parameters is to change the risk manager's paradigm: to maximise health and quality of life rather than just to minimise risk.

This recommendation can be seen to reinforce the European Commission Communication on the Precautionary Principle and its implementing guidelines. The Communication prescribes principles for the selection of risk management measures in general and in cases where uncertainty in the risk assessment requires resort to the precautionary principle. Social and economic concerns should be taken into account when weighing alternative policy options. Finally, although there are general legal provisions on the division of power and roles between experts, EU institutions and Member State competent authorities in decisionmaking processes, little is said on the formal involvement of interested affected parties, such as, for example, the crucial role firms play in developing safety assessment data for their new products (table 1).

The EU food safety system also falls short of more general principles of good governance stated in 2002, in Romano Prodi's attempt to bring EU institutions closer to the citizenry in nine communications on governance ${ }^{2}$, which strengthened and generalised prior calls for

\footnotetext{
${ }^{2}$ Nine steps were adopted in 2002 to improve governance (including food safety regulation) including
}

openness $^{3}$. One 'Commission Communication' recommended diversity on expert advisory committees [7]. Another advocated formal impact assessments of new proposals, emphasising shared definitions and objectives. Guidelines gave criteria for the analysis of envi-

the Communication from the Commission Towards a Reinforced Culture of Consultation and Dialogue: General Principles and Minimum Standards for Consultation of Interested Parties by the Commission. COM (2002) 704. Communication from the Commission on the Collection and Use of Expertise by the Commission: Principles and Guidelines COM (2002) 713; Communication of the Commission on Impact Assessment COM (2002) 276; Communication from the Commission Action Plan "Simplifying and Improving the Regulatory Environment COM (2002) 278; Commission Communication: Better Monitoring of the Application of Community Law COM (2002) 725; Proposal for a Council Decision cedures for the Exercise of Implementing Powers conferred on the Commission (amendments to the Comitology Procedure) COM(2002)719; Communication from the Commission The Operating Framework for the European Regulatory Agencies COM (2002) 718.

${ }^{3}$ In the field of environmental policy, provisions for greater transparency were implemented earlier, and include the 1997 Commission Decision on Public Access to Documents of the European Environment Agency. The 1997 Council Resolution on Drafting, Implementing and Enforcing Community Environmental Law recommended increased participation in the form of stakeholder consultation 'at an early stage on concrete legislative proposals.' Amending Decision 1999.468/EC laying down Pro- ronmental, economic, social, public health and ethical implications [8].

In conclusion, in EU policy on risk analysis, the scope of the current risk assessment and decision-making process is narrow as it focuses on single risk issues. Risk management, described in policy documents as the process of weighing of alternative decision options, is mainly implicit: there are no formal guidelines, nor requirements to leave a visible paper- or web-trail on the basis for decisions (only opinions of expert committees are now posted on the web).

Many recommendations on good governance have not been translated into current practise. The SAFE FOODS consortium is developing recommendations to bridge this gap.

\section{The SAFE FOODS project}

The SAFE FOODS project is a research platform with thirty-seven partners from twenty-one countries, including China and South Africa. The total budget is 14.6 million euros, from which over two thirds come from the European Union $6^{\text {th }}$ Framework Programme for Research and Technological Development. The project runs from 2004 to 2008.

Research under the SAFE FOODS platform is divided into six workpackages:

(1) the development of new analytic tools by adapting modern profiling technologies for use on foods;

(2) the design of new working procedures for early identification of emerging microbial and chemical risks in transnational food production chains;

(3) the improvement of models for understanding health impacts at the population level of combined exposures to beneficial nutrients and natural and chemical toxicants;

(4) the development of more effective communication strategies for the information exchange between experts, regulators and stakeholders (including producers, retailers and consumers);

(5) the investigation of the role of diverse EU institutions involved in the governance of food safety;

(6) integration of all work into an improved risk analysis framework.

\section{Profiling technologies to better understand what's in plant-derived foods}

The first research group is assessing the utility of profiling technologies to provide an expansive analysis of gene (transcriptomics), protein (proteomics) and metabolites (metabolomics) using maize and potato as model crops. The work includes an analysis of variation caused by the breeding system, natural genotypic varia- 
tion, and variation due to geographical location and crop management practise. Through the development of comparative profiling databases, which can be expanded and evolved by the international community, a fuller evaluation of the compositional variation of raw materials will emerge. This information can be used to benchmark any measured differences between a particular crop against the extent of "acceptable" variation within the framework of a history of safe use of the crop species in question.

Several thousand crop samples have been collected and analysed, covering organic low input and conventional agricultural systems, a range of varieties and also genetically modified (GM) and non-GM crops. Crops were grown in both field and glasshouse trials primarily in the regions of the UK, Germany, Poland, Italy, and South Africa. Metabolomics involves the use of state-of-the-art Gas Chromatography-Mass Spectrometry (GC-MS), Liquid Chromatography-Mass Spectrometry (LC-MS) and Nuclear Magnetic Resonance spectroscopy (NMR). The combined use of these diverse tools allows broadening the categories and numbers of compounds that can be analysed. Proteomics focuses on the use of twodimensional gel electrophoresis to analyse ca 1,000 polypeptides, whilst transcriptomics focuses on the use of potato and maize gene microarrays. All data are analysed by professional statisticians using multivariate and univariate approaches.

Challenges include that the breadth of compounds that can be detected will still be limited given the fact that many thousands of metabolites exist in plant cells. Furthermore, there is not necessarily a direct relationship between the metabolite and the gene [9]. Combined analysis of transcript and metabolite profiling by pairwise correlation analysis indicated that only 25 to $36 \%$ of the variation in metabolite level was attributable to variation in transcript level. The science has not progressed sufficiently to allow the outputs from each technology to be understood within the framework of a biological systems approach. However, the results from this group point to the fact that despite the obvious challenges surrounding the integration of data from various profiling technologies the "omics" approaches clearly facilitate a level of analysis hitherto not possible. They allow gaining a better understanding on where the major sources of variation in gene, protein and metabolite expression arise.

\section{Tackling emerging risks promptly}

The second strand of research concerns the early detection and assessment of emerging microbial and chemical hazards in food and feed chains. The group in charge has devel- oped a web-based transfer point for emerging risks that contains information on more than 300 national and EU projects dealing with relevant food safety issues relevant for emerging risks. Furthermore, over 360 experts on food safety have registered from 260 organisations in 35 countries registered upon invitation in a database; all expressed their willingness to be contacted in cases of emergencies. EU experts on food safety registered upon invitation, but interestingly, experts from outside the EU responded as well. Several organisations, both national and European (e.g. EFSA) have shown their interest in becoming potential users of this database. Papers with literature reviews and recommendations on how to address specific emerging chemical and microbial hazards have been submitted for publication in a special, dedicated issue of the journal Food and Chemical Toxicology to provide input for the design of a working procedure for the identification of emerging food safety risks. The group will also publish a paper with a critical discussion of existing rapid alert systems for merging microbial risks and mycotoxins, as well as the EU Rapid Alert System for Food and Feed.

\section{Towards cumulative and aggregate exposure assessments}

For improved cooperation and networking between the EU Member States and the EU institutions, data sharing and the adaptation of harmonised risk assessment procedures are key. This strand of research concerns an approach that promises to respond to all these demands, and at the same time to address the difficult issues of assessment of cumulative exposure, risk-benefit questions and risk tradeoffs. This strand has three parts: First, the development of a probabilistic integrated risk model in which ranges of exposure to compound via food can be directly linked to possible detrimental health effects. These assessments take into account the variability in dietary exposure and sensitivity within a population, and the uncertainly in the input variables and the resulting outcomes. Second, the development of an electronic platform of food consumption and residue databases all linked to probabilistic software via the Internet. This platform facilitates Pan-European modelling of ranges of exposure in which national and international exposure calculations are performed in a harmonised fashion. Furthermore, with this platform it will be possible to exchange data, so that countries with data scarcity can supplement their data with that of other countries. Third, the group is developing approaches to use the probabilistic models of exposure and sensitivity in situations where consumers are exposed simultaneously to more than one chemical and in which the risk manager has either to balance the effect of the risk (or benefit) of one compound against another or to consider cumulative effects of compounds with the same mechanism of action.

Today, risk assessments in the EU are mainly performed using point estimates of both exposure and health effects: a certain level of exposure (high level, mean level) is compared to with a toxicological reference value (e.g. Acute Reference Dose, Acceptable/Tolerable Daily Intake). In the period 2002-2005 there has been much effort in promoting the acceptance of probabilistic exposure modelling within Europe, including training of EU regulators themselves, but many remain apprehensive. This is for a large part due to unfamiliarity with the method and a lack of guidelines on how to interpret the results in relation to health effects. However, complicated risk assessment issues have emerged during the last few years, such as cumulative assessments, risk-benefit and risk trade-off analyses, integration of exposure modelling with effect modelling (Margin of Exposure) and multi-source exposure, and the continuing demand of addressing uncertainty and variability when assessing dietary risks.

\section{Improved communication on risks, benefits and uncertainties}

The fourth strand of research used focus groups and follow-up interviews to identify key factors in the evaluation of food risk management practises according to consumers and experts. Conclusions from the analysis of similarities and differences in which of these factors are considered key are the basis for recommendations on improved communication. Qualitative and quantitative studies allowed modelling the key determinants of consumer confidence in food risk management practise. Findings to date suggest that an important issue for consumers is whether the motivation of food risk managers is primarily consumer health protection, or whether they are acting to promote their own economic or political interests, or those of other actors in the food chain. Furthermore, this research confirms prior findings that consumers perceive food risk managers to be more trustworthy if they come from a similar background to consumers, or are identified as having similar interests or values to those held by consumers. Different countries and potential food hazards were included in this study in order to examine potential differences in impact of communication efforts across different food hazards and countries.

\section{Institutional provisions for risk analysis}

The last strand of research concerns institutional aspects of risk analysis. This group focussed specifically on the treatment of scientific uncertainty, the use of the precautionary 
principle in risk analysis; the handling of risk issues that are subject to strongly divergent cultural attitudes, political perspectives or economic interests; the quest for more openness and transparency during the entire risk analysis process; and the design for effective means and structures for stakeholder and public involvement. The empirical analysis shows that with the growing efforts in Europe to segregate risk assessment from risk management responsibilities, critical interfaces between the two activities increasingly become apparent, especially when responsibilities are divided between different institutions. The comparative study indicates that there are two points in the risk governance process which in particular require interaction and coordination at the stage of framing when the risk governance process is initiated, the questions and tasks are defined and the terms of reference are specified; and after the assessment has been carried out, when scientific advice needs to be communicated to different audiences and considered in relation to judging the seriousness and acceptability of the risk and the need for risk management measures. In order to improve the interaction between assessment and management, and with the aim of rendering this information exchange more transparent and inclusive, this team has proposed different institutional solutions to formally organising the interfaces of mandating/framing and evaluation as communication and cooperation platforms bringing together assessors, managers, and key stakeholders. The social and political viability of these options which vary with regard to their degree of formalisation is currently being reconsidered in the light of the feedback gained at the four stakeholder workshops.

\section{An improved framework for risk analysis}

The development of the new integrated risk analysis framework is the central activity that ties together the diverse strands of research under the project. First, we have identified gaps between current frameworks for risk analysis, policies on good governance and the practise of implementation of food safety regulation. In order to address these gaps we combine research and expertise in the natural and social sciences from SAFE FOODS members with insights from practitioners. We consult practitioners from governments, civil society organisations and industry using different methods including interactive workshops and Delphi survey questionnaires throughout the course of the project ${ }^{4}[10]$. The new improved risk analysis framework, including information pre-

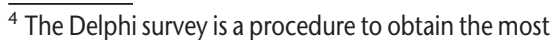
reliable consensus opinion of a group of experts, using consecutive rounds of survey questionnaires.
}

sented in this document, is therefore subject to change until the conclusion of the project in 2008.

\section{The SAFE FOODS framework}

This new integrated framework describes an iterative decision-process with four stages: framing, risk-benefit assessment, evaluation, and risk management (figure 1). The addition of formal framing and evaluation stages is new compared to current practice.

At the framing stage of the SAFE FOODS framework, interested parties, experts and officials work together to gain an initial shared understanding of the issue, objectives and broad courses of regulatory action. Areas of consensus and dissent are documented, which forms the basis for planning the decision-process. This includes defining the scope of the assessment and terms of reference for the experts, proposing criteria for ranking regulatory options, and proposing monitoring indicators. The activity of framing per se, is nothing new. Although there may be little or no formal system for framing, staff of the European Commission and the risk assessment authority for food safety issues of the EU - the European Food Safety Authority (EFSA) do talk to each other on an ongoing basis during all stages of decisionmaking, even if this is not always formally documented. Staff from the European Commission takes part in EFSA Scientific Panel meetings. Likewise, staff from EFSA takes part in European Commission meetings. Stakeholders are often consulted including by organizing workshops on specific issues conducted by EFSA and by DG SANCO. In framing policy and legal issues this information is considered together with information from other meetings with stakeholders. Furthermore, the European Commission just established in the form of the 'Advisory Committee on the food and feed chain'. Most practitioners from the EU institutions feel that proposals for improvement should focus on remits and activities under existing structures. On the other hand, most practitioners from industry and NGOs would welcome an opportunity to provide more formal input at the early stages of issue definition

The procedure has four defining features: anonymity, iteration, controlled feedback to the group on results after each survey round, and statistical aggregation of the responses. The iteration combined with anonymity facilitates it for individuals to change their views with additional emerging information. Classically, questions in the first survey round are more general and open; subsequent rounds become increasingly structured based on analysis of data from previous rounds to identify areas of dissent and consent. and framing. Current Commission methods of soliciting stakeholder input, and in particular the European Commission's commonly used internet-based questionnaires, were considered amenable to improvement and the need for more flexibility and transparency indicated for issues of concern.

The SAFE FOODS framework recommends that in future the risk-benefit assessment should not only pertain to single pre-identified risks, but to health impacts in general (including health benefits), environmental, economic, social and ethical impacts, and their distribution. SAFE FOODS research develops improved methods and models for risk assessment. Research on profiling methods for analysis of plant-derived foods is one step towards considering whole foods in the context of what humanity has been eating rather than focussing on risk of single substances. Models for the integrated probabilistic assessment of exposure and effect will allow for improved assessment of cumulative and aggregate exposures.

However, in practise this can be only stated as a long-term goal rather than a procedural requirement for tomorrow. In particular in the area of health-benefit assessment new and improved methods are required. Methods for risk-benefit assessment should be part of research agendas. New assessment methods including the use of QALY's or DALYs or other tools from decision science in food safety should be further explored. The future possibility of considering health risks and benefits in management of issues where this is relevant is generally regarded as a huge step forward. Given the current strict separation of risk assessment and management at the EU institutions, the role of EFSA and current Scientific Panels is restricted to estimating probability and severity of health effects. Activities of linking such data to QALYs and health utility data, or launching wider formal assessments of social and economic impacts would need to find an institutional home. These activities could also be considered part of the 'evaluation stage' which is proposed as a new intermediate stage between risk assessment and management. Evaluation is a participatory process in which interested parties, experts and officials use the assessment outcome to compare the risks, costs, and benefits and their distribution. The outcome of the evaluation is a report with recommendations on her risk management measures from multiple perspectives.

In the current system there is no such stage in decision-making as the proposed 'evaluation stage'. There are practises for coming from assessment opinions to management decisions, but they are opaque. Sometimes data from the health risk assessment are the main factor considered in weighting decision 


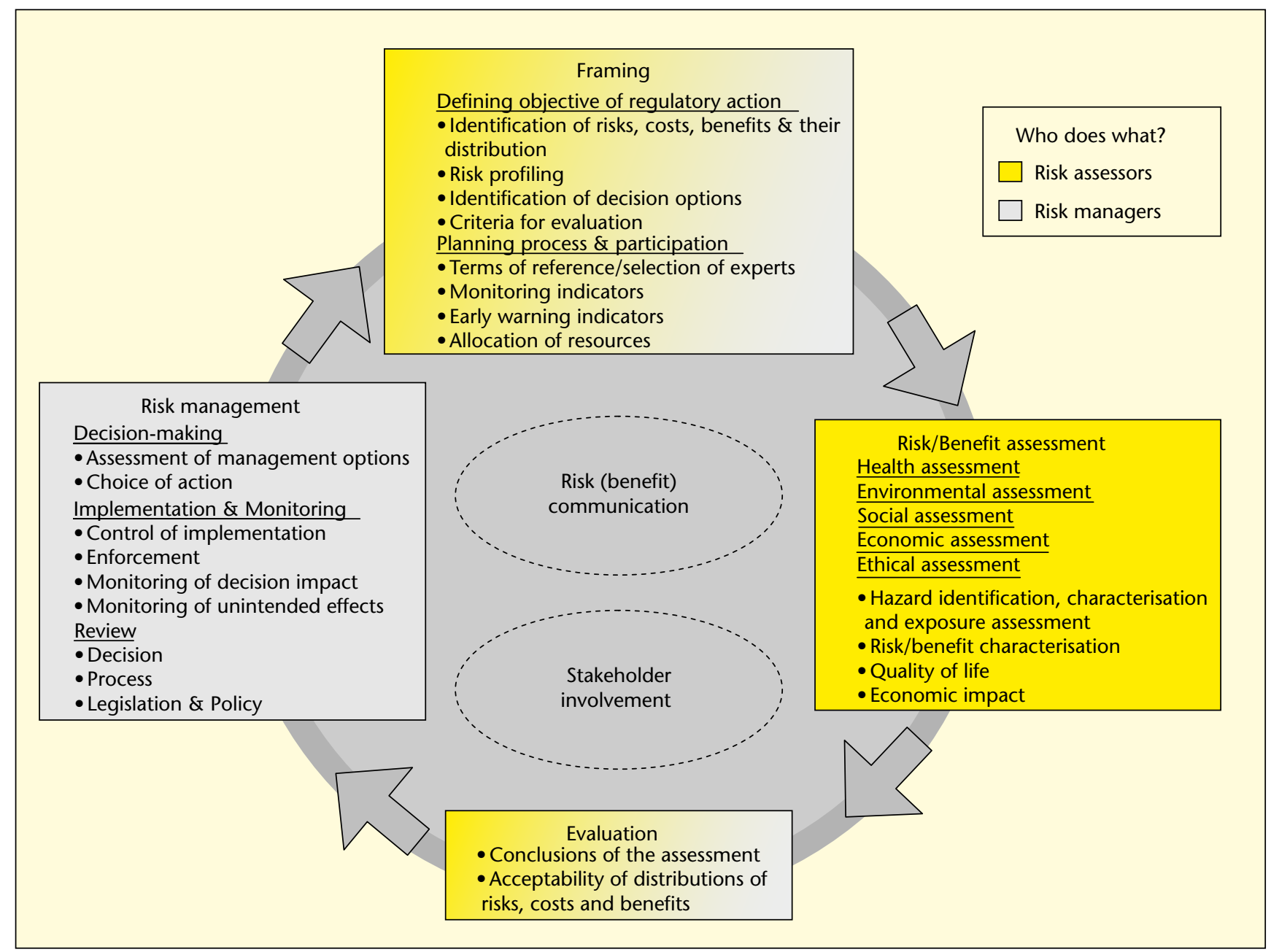

Figure 1. The SAFE FOODS cycle.

options, sometimes they are not. Managers at the Commission in drafting a proposal for a decision need to consider other aspects, these can include the technical feasibility of implementing proposed measures, trade considerations, including specific rules of the Codex Alimentarius, and, where relevant, impacts on developing countries. How information and view points from various stakeholders can be considered varies according to these other restrictions and the time required for and cost of soliciting stakeholder input on a specific issue. Regulatory Committees with representatives of Member State competent authorities vote on proposals; votes are placed taking into consideration stakeholder networks at the national level with whom often good relations exist. Several risk managers at EU and national level however admitted their jobs would be easier if the had more concrete information on consequences of a set of management options. Many practitioners agree that a separate evaluation step would re-enforce transparency of the risk analysis process.
The Evaluation stage recommended by SAFE FOODS can in some ways be considered as the conclusion of the assessment. Evaluation should do ranking of options - based on the risk assessment data and other stakeholder input. Mangers should drive the evaluation to be sure they get what they need for making decision. Different procedural options could be considered for evaluation: open consultation using the internet or face-to-face meetings. The value of evaluation would be to make risk managers aware of irreconcilable views, and of where a majority in a diverse group with the characteristics of the evaluation team would place their points in ranking options.

Risk management in the current version of the SAFE FOODS framework includes decisionmaking, implementation, monitoring and review. Risk management involves the final selection of one regulatory option, in the light of the assessment and evaluation. The new framework does not alter current roles and distributions of power between institutions. Monitoring indicators are defined based on proposals at the framing stage, and monitoring plans are defined and implemented as at present. Review pertains not only to the impacts of the decision itself, but also to the process by which the decision was made, and the legislation under which the issue is regulated. Moreover, improved approaches for the early identification of risks developed through SAFE FOODS research will allow more proactive action by officials and interested and affected parties above and beyond what's required by law (box 1).

\section{Stakeholder participation and public consultation}

Looking more specifically at questions relating to 'stakeholder engagement' in the EU institutions, one Commission official compared the EU institutions, and the individual European Commission services to a flock of administrative geese that fly towards improved engagement at different speeds and on different trajectories. Most practitioners consulted agree 


\section{Box 1}

\section{Overview of elements to be considered in the assessment}

\section{Elements in health assessment}

Effect

Mechanism of action

Routes of exposure/dietary intake considerations

Diverse sensitivity of potentially exposed populations

\section{Elements in environmental assessment}

Air, water and soil quality, climate, renewable or non-renewable resources, biodiversity and landscapes

Land use

Waste production, generation and recycling

Likelihood or scale of environmental risks

Mobility, transport use and use of energy

Animal and plant health

\section{Elements in the economic assessment}

Competitiveness, trade and investment flows

Competition and internal market

Operating costs and conduct of business

Administrative costs on businesses and others

Property rights

Innovation and research

Consumers and households

Specific regions or sectors

Third countries and international relations

Public authorities

The macroeconomic environment (economic growth and employment, conditions for investment and functioning of the market, direct or indirect inflationary consequences)

\section{Elements in the social assessment}

Public health and safety (including use of tools for cost-benefit and cost-effectiveness assessment of health impacts characterised in the health assessment)

Potential impact on public opinion

Employment and labour markets

Standards and rights related to job quality

Social inclusion and protection of particular groups

Equality of treatment and opportunities, non-discrimination

Governance, participation, good administration

Access to justice

Media (e.g. if monitoring of health hazard with media reporting of results is imposed as a condition for approval...)

Crime, terrorism and security

Access to and effects on social protection, health and educational systems

\section{Elements in the ethical assessment}

Religious considerations

Animal welfare

Animal health

Equity/distributional issues

These are extracts from more detailed tables presented in the European Commission Guidelines on Impact Assessment*

* See note 3.

that stakeholder involvement in risk analysis is indispensable, but called for a deeper analysis on how this happens already today, and on what the value and drawbacks would be of further formalizing this.

On stakeholder engagement, the members of the SAFE FOODS team are currently working out how to institutionally combine several seemingly hard to reconcile demands and establish a SAFE FOODS framework that fits within existing policy and legal provisions and practise at EU-level. Any new recommendations need to build on existing provisions, and their compatibility with current EU law needs to be discussed. For example, apart from closer reference to the General Food Law, it should also be considered how the SAFE FOODS framework would be implemented within the newly proposed authorization procedure for packaging, flavours, additives and enzymes. And how does the new framework relate to the newly revised Novel Foods Regulation? The legal framework does much to define the relations between risk assessors and risk managers. There is a need to analyze the current system in more detail, to anticipate new provisions, and to assess own proposals as to whether legislative change would be required for implementation.

This work very much runs in parallel with work on the same topic by the European Commission and EFSA. The SAFE FOODS approach will only be of value if all can be integrated in the end. The European Commission just obtained recommendations from its 'Healthy Democracy' initiative, in which a group of experts was asked how current practises of stakeholder consultation at the Commission might be improved. The main problem identified by this group was the lack of representation of diverse groups of stakeholders across Member States. Organized civil society actively seeking direct input in EU policy, usually come from two or three larger Member States with a strong or long-standing tradition of participatory politics (such as the UK). The same few groups usually also have the loudest voice in Brussels based EU-level groups. Input from across all $27 \mathrm{Mem}$ ber States would be preferred as cultural variations are expected, in particular on foodrelated matters. One main challenge is thus 'how to engage the unengaged'?

The risk assessment/management/stakeholder interface seen from the perspective of practitioners from within the system at present looks as follows: DG SANCO officials often participate in meetings of scientific expert panels. In theory, the definition of expertise depends on what is at issue. In practise, EFSA has eight established standing Scientific Panels on food safety challenges such as additives and GMOs. The discussion on whether lay members should be included on expert panels at EFSA such as in the UK FSA has been long-standing - but no change of this is expected in the near future. The argument that this may help in the presentation of expert opinions to make them more accessible and a more suitable democratic base is often countered with the fact that timelimited expert discussions will be in less depth and more time of experts will be devoted to explaining basics. The remits of the UK FSA and the US FDA, agency where this is common practise in risk management, whereas EFSA's remit is restricted to risk assessment. Furthermore, strong emphasis on institutional separa- 
tion of risk assessment and management and boundaries drawn in the remit of EFSA will likely remain in place. This will also affect who participates in assessments and what is considered as part of the assessment. One reason that was most often forwarded by UK participants was that inclusion of consumer groups on expert committees for improved communication do not treat all members equally. Breadth of scientific disciplines may also help crossquestioning. The question was raised whether the recent practise of publishing draft opinions for public comments on the web can be seen as an alternative approach to help experts better address public opinion - across the EU. What would be the advantages and disadvantages. The final SAFE FOODS report will also address this question.

At EFSA, initiatives and events seeking stakeholder input are conceived of as separate activities from meetings of scientific expert committees. There are four different types of formal events that serve to inform EFSA staff and scientific experts on panels about stakeholder views, including Member State authorities, and connect them to experts on specific issues in other world areas. First, there are 'stakeholder colloques' which serve as platform for an open dialogue with as many stakeholder $s$ as there are. Second, there are public consultations via the web - these are usually held on 'hot topics' such as cloning, GMOs, pesticides, feed additives, genotoxic and carcinogenic substances. In general, EFSAs main worry is who the stakeholders are EFSA should be talking with - and whether there is a wider audience EFSA should try to reach - at the national level, without stepping on the toes of national authorities who likely already have relationships with them. As experienced by DG SANCO stakeholders eager to participate usually originate from one to three main EU countries, they are far from distributed across all 27 Member State. But is it true that there is no stakeholder input into assessments?

Assessment data packages for industry products can be conceived as a joint outcome from iterative rounds of collaboration between assessors and firms. The goal of assessors and large firms with a name to protect is similar: products with a high potential to harm should not be placed on the market. Many practitioners feel that in most cases, regardless of the type of issue, there is the need to consider data and interpretations from diverse stakeholders.

One main first recommendation is that in all cases the objective of stakeholder involvement needs to be clear. Three fundamentally distinct objectives for stakeholder engagement could be distinguished: to better understand impacts and costs of decision options (i) to identify ways for improving consumer choice; (ii) to facilitate adoption of good practises associated with the implementation of the decision in industry; and (iii) for improved resource allocation across public health measures. One suggestion to simplify stakeholder definition across diverse issues was to distinguish between two groups of issues for which the administrative process, and in particular the definition of stakeholders and ways of their participation is fundamentally different: industrial products for which applicants provide most assessment data, and often an assessment report with normative recommendations; and natural contaminants for which this is not the case.

The issue of public participation or consultation for each stage of the risk analysis process should also be considered in future work. The increasingly common use of web-based public consultation on draft policies, rules or opinions was welcomed as one solution for trying to tease out prevailing divergences on specific issues across Member States. The method, and in particular questionnaires with few spaces for open critique, was however also seen to have severe limitations. Modalities for more open electronic fora for stakeholder dialogue are also being considered in the project.

\section{Conclusion}

In sum, the SAFE FOODS project develops an integrated framework for risk analysis that is more transparent and accountable. Three main differences to current frameworks are: (1) expansion of the scope of the formal risk assessment to include distributions of benefits and costs; (2) more formal stakeholder participation; and (3) improved risk communication and publicly accessible reports at each stage of the process. We are developing better tools for compositional analysis of foods, probabilistic modelling of exposures and health impacts, and risk communication. Our approach to development of the new framework is innovative and combines research and expertise in the natural and social sciences from SAFE FOODS members, and repeated consultation of practitioners. Integrating practitioners in the development of the framework is intended not only to ensure practicability, but also for dissemination and to enhance the chances of adoption. Current work focus is on improving the linkage with current institutional and legal provisions at EU level and how exactly the model fits and what would require changing.

Several other issues still need to be better addressed. Perhaps the most important issue that will require more in-depth consideration is the compatibility of the proposed framework with international agreements and in particular the agreements under the World Trade Organisation (WTO). Codex is struggling with the same issues of broadening the scope of assessment and engaging stakeholders. For example, WTO is now taking an initiative to find out the impact of different Maximal Residue Levels (MRLs) across different countries and to better understand what type of data is required to judge this. A more detailed analysis of responses from the Codex Commission and how these relate to the SAFE FOODS framework was considered beneficial by many participants. Almost any regulatory requirements can in principle be applied by Codex Member Nations, provided they are applied in a nondiscriminatory manner as between domestic producers and imported products. But in practise, some provisions may cause more offence to politicians in other world areas, than others. The issue of fair trade needs to be considered in more detail. International discussion and feedback would help.

Last but not least remains the question -- how can single issues be better placed in the larger context of resource allocation across public health measures? -- This would be helpful for the planning of the decision-process, data requirements and weighting potential regulatory options and their costs and impacts. Answers to this question would also help addressing concerns on consistency and proportionality and effective allocation of resources across issues and over time, as required by the General Food Law. This link between single issues and the health policy context is insufficiently addressed in present systems. In fact, it is a global problem. The concept of 'margins of exposure' may help to prioritize issues. The systematic adoption of tools from decision analysis such as Quality of Life Year measures of the utility of different health states may play another part in addressing this challenge of placing primacy on health impact and equity in the resource allocation to public health issues.

Strategic considerations on the development of new technologies should also somehow be taken into account. Finding even only partial answers to these problems remains a tall order. We hope to provide more insights on these issues in the final SAFE FOODS framework to be published in the course of 2008. If you have comments and suggestions on this work in progress, please do not hesitate to send them to the corresponding author of this paper.

Acknowledgments. We thankfully acknowledge the contributions of the whole SAFE FOODS consortium, and all practitioners who engaged in our feedback workshop and filled in questionnaires. 


\section{REFERENCES}

1. COUNCIL OF THE EUROPEAN UNION. Press release EC/6762/06, 9 March 2006.

http://europa.eu.int/rapid.

2. NATIONAL RESEARCH COUNCIL. Risk assessment in the federal government: managing the process. Washington (DC): National Academy Press, 1983.

3. FAO/WHO. Risk Analysis in Food safety Standard Setting. Geneva: WHO, 1995.

4. FAO/WHO. Risk management and food safety. Report of the Joint FAO/WHO Expert Consultation. Rome, 27-31 January 1997. Rome: FAO, 1997.

http://www.fao.org/es/esn/risk/risktext.htm.
5. EUROPEAN COMMISSION. Communication of the European Commission on Consumer Health and Safety COM. Brussels: European Commission, 1997.

6. SCIENTIFIC STEERING COMMITTEE. Report on Setting the Scientific Frame for the Inclusion of New Quality of Life Concerns in the Risk Assessment Process. Brussels: European commission, 2003.

7. EUROPEAN COMMISSION. Communication of the European Commission on the Collection and Use of Expertise by the European Commission: Principles and Guidelines' COM (2002). 713 final. Brussels: European Commission, 2002.
8. EUROPEAN COMMISSION. Impact Assessment Guidelines. 15 June 2005 SEC (2005) 791. http://europa.eu.int/comm/secretariat_general/ impact/docs/SEC2005_791_IA\%20guidelines annexes.pdf.

9. URBANCZYK-WOCHNIAK E, LUEDEMANN A, KOPKA J, et al. Parallel analysis of transcript and metabolic profiles: a new approach in systems biology. EMBO Rep 2003; 4: 989-93.

10. ROWE G, WRIGHT G. The Delphi technique at a forecasting tool: issues and analysis. Int I Forecast 1999; 15: 353-75. 